\title{
Exposure of abattoirs workers to rift valley fever virus infection in Southwestern Saudi Arabia
}

\author{
Tarik A. Al-Azraqi ${ }^{1}$, Awad A. El Mekki $^{2}$, Ahmed A. Mahfouz $^{3^{*}}$ \\ ${ }^{1}$ Departments of Internal Medicine, College of Medicine, King Khalid University, Abha, KSA; tark4u2u@hotmail.com \\ ${ }^{2}$ Departments of Clinical Microbiology, College of Medicine, King Khalid University, Abha, KSA; \\ aaelmekki@gmail.com \\ ${ }^{3}$ Departments of Community Medicine, College of Medicine, King Khalid University, Abha, KSA; \\ *Corresponding Author: mahfouz2005@gmail.com
}

Received 25 October 2012; revised 27 November 2012; accepted 5 December 2012

\begin{abstract}
Objective: To measure seroprevalence of Rift Valley Fever virus infection among abattoirs workers in Southwestern Saudi Arabia. Materials and Methods: Abattoirs in the region (Jazan, Aseer and Al Qunfuda) were visited. Veterinarians and butchers were studied. Blood samples were then taken and tested for RVF-specific IgG and IgM (ELISAs). Results: The present study included 62 abattoir workers. None of whom tested were positive for RVF specific IgM. The overall prevalence of RVF IgG among butchers reached 8\% (95\% Cl: 1.3 - 75.8). Among the 31 Bengali butchers 3 were RVF IgG positive giving a prevalence of $9.7 \%$ (95\% Cl: 2.0 - 25.8), while among four Saudi butchers one was RVF IgG positive (25\%, 95\% Cl: 1.3 - 75.8). Conclusions: The study documented the lack of recent RVF activity among abattoirs workers. High-risk, occupationally exposed abattoir workers represent a useful sentinel population for surveillance of RVF, especially in the absence of clinical disease.
\end{abstract}

Keywords: Rift Valley Fever; Sero-Epidemiologic Studies; Abattoirs; Saudi Arabia

\section{INTRODUCTION}

Rift valley fever virus infection (RFV) outbreaks have been reported in the southern region of Saudi Arabia $[1,2]$. By the end of the outbreak (22 September 2001) the total number of hospitalized cases amounted to 884 of whom 843 were laboratory confirmed [3]. No RVF outbreaks or human cases have been reported in the Kingdom of Saudi Arabia since then.

Slaughterhouse work involves stressful and tiring tasks. Those workers suffer from serious occupational injuries and health problems including musculoskeletal disorders, zoonoses, skin conditions and injuries related to animals and sharp instruments. Studies in developed countries showed that abattoir workers are generally lowskill staff have no control over their job tasks and may not be aware of the determinants affecting their health [4].

The objective of the work was to estimate seroprevalence of Rift Valley Fever virus infection among abattoir workers in Southwestern regions of Saudi Arabia.

\section{MATERIALS AND METHODS}

\subsection{Study Area}

The study area (Figure 1) included Jazan, Aseer regions and $\mathrm{Al}$ Qunfuda area in the Makkah region. Jizan area is located in the southwest of Saudi Arabia, bordering the northwestern region of Yemen. The Aseer region is located in the southwest of Saudi Arabia The region extends from the high mountains of Sarawat to the Red Sea, and lies few kilometers from the northern border of neighboring Yemen. The Aseer region is bordering Jazan and is located to its northeast. Al Qunfuda is a further northward extension of this coastal plain in the Makah region [5].

\subsection{Study Population}

Abattoirs within the study areas were identified. Communication with preventive sectors in the concerned directorate of health affairs and local municipalities were made. Letters of approval (explaining the objectives of the project and asking for their consent and cooperation) were given to each abattoir director to ensure full cooperation. During late 2008 and through a series of field trips, abattoirs were visited. Workers (Veterinarians, butchers and clerks) present during the visit were included in the study. Informed consents were obtained from each individual to be included in the present study. 


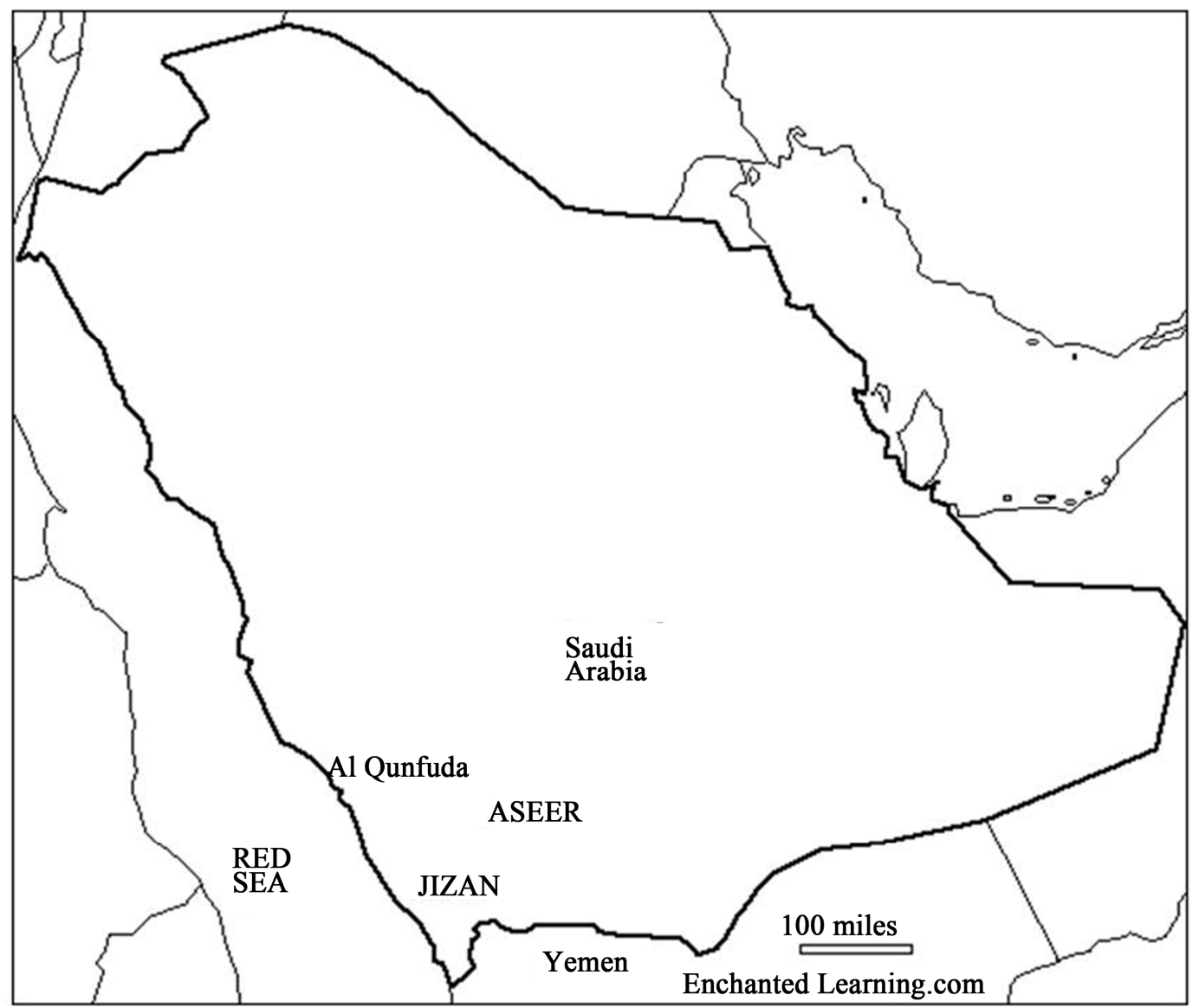

Figure 1. Map of Saudi Arabia showing the study area; Jizan, Aseer and Al Qunfuda area.

\subsection{Blood Sampling}

About 5 - $10 \mathrm{ml}$ venous Blood samples in plain tubes were taken from each participant and were allowed to clot at room temperature (range $18^{\circ} \mathrm{C}$ to $20^{\circ} \mathrm{C}$ ). Samples were then centrifuged at $10,000 \mathrm{rpm}$ for 10 minutes and the separated sera were alliquotted into 2 portions and stored at $-20^{\circ} \mathrm{C}$ until transported in Styrofoam boxes containing dry ice (solid carbon dioxide, $-40^{\circ} \mathrm{C}$ ) to the Virus Lab of Abha college of Medicine. All samples were received there in a frozen state, and were grouped by the area of collection and stored in classified boxes in deep freezers at $-20^{\circ} \mathrm{C}$.

\subsection{Serologic Tests}

\section{Testing of Sera for RVF-Specific IgG and IgM Antibodies}

RVF kits were provided as bulk reagents to be further processed prior to testing. The kit "RVF IgG ELISA" (Batch \# 2007-11), is manufactured, standardized and provided by the National Institute of Communicable Diseases, Special pathogens Unit, Johannesburg, South Africa. All relevant reagents were supplied with the kits including the controls. RVF-specific IgM assays were performed utilizing kits from the supplier mentioned above (RVF IgM ELISA, Batch \# 2007-11). The manufacturer's protocols were strictly followed in performing and evaluating the results.

\subsection{Statistical Analysis}

Data were coded, validated and analyzed using SPSS $\mathrm{PC}+$ version 13 software package. Frequency, percentage, arithmetic mean, median, mode and $95 \%$ confidence intervals of the estimate were used to present the data.

\section{RESULTS}

\subsection{Description of the Study Sample}

The present study included 62 persons working in abattoirs in the study regions (Table 1). They included 50 butchers $(80.6 \%), 10$ veterinarians $(16.1 \%)$ and 2 clerk workers $(3.3 \%)$. Their age ranged from 19 years to 60 years with an average of $36.77 \pm 10.29$ years and a median of 35 years. The majority of butchers were Bengali $(31.62 \%)$, followed by Indians $(5.10 \%)$, Saudis $(4.8 \%)$ Sudanese (4.8\%) and Egyptians (3.6\%). Veterinarians 
Table 1. Seroprevalence of RVF IgG among the study sample of abattoirs workers in Southwestern Saudi Arabia $(\mathrm{N}=62)$.

\begin{tabular}{cccccc}
\hline Variables & No. Examined & $\%$ & No. Positive & Prevalence (\%) & $95 \%$ Confidence Interval \\
\hline Occupation Group & 50 & 80.6 & 4 & 8 & $2.8-17.4$ \\
Butchers & 10 & 16.1 & 0 & 0 & - \\
Veterinarians & 2 & 3.3 & 0 & 0 & $1.8-15.7$ \\
Clerks & 62 & 100 & 4 & 6.5 & $1.3-75.8$ \\
TOTAL & & & & 25 & $2.0-25.8$ \\
Nationality of Butchers & 4 & 8 & 1 & 9.7 & - \\
Saudi & 31 & 62 & 3 & 0 & - \\
Bengali & 5 & 10 & 0 & 0 & - \\
Indian & 4 & 8 & 0 & 0 & - \\
Sudanese & 3 & 6 & 0 & 0 & - \\
Yemeni & 3 & 6 & 0 & 8 & \\
Egyptian & 50 & 100 & 4 & & \\
TOTAL & & & & & \\
\hline
\end{tabular}

were mostly Egyptians (8.80\%) and Sudanese (2.20\%). The clerks were Saudis. The period of stay of non Saudis in slaughter houses ranged from 3 year to 35 years with an average of $10.38 \pm 7.24$ years and a median of 8 years. The majority of workers $(39,62.9 \%)$ had no complaints at all in the six months period prior to the survey. The most frequent complaints were back pain $(9,14.5 \%)$ followed by headache $(4,6.5 \%)$.

\subsection{Sero-Prevalence of Rift Valley Fever Virus Infection}

\subsubsection{Seroprevalence of RVF-Specific IgM}

None of the 62 samples tested for Rift Valley Fever IgM, were positive giving a Seroprevalence of zero \%.

\subsubsection{Seroprevalence of RVF-Specific IgG}

Out of 62 samples tested for Rift Valley Fever IgG, four samples were positive giving a Seroprevalence of $6.5 \%$. The prevalence of RVF IgG among butchers reached $8 \%$. On the other hand, the prevalence among veterinarians and clerk workers was zero percent. Among the studied four Saudi butchers one was positive (25\%). Among the 31 Bengali butchers 3 were positive giving a prevalence of $9.7 \%$. On the other hand, none of the studied Egyptian, Sudanese and Indian butchers was found positive. The study showed that the 4 positive cases of Rift valley Fever IgG had no complaints at all in the past 6 months.

\section{DISCUSSION}

Abattoir workers and herdsmen are at a high risk of acquiring RVF virus infection [6,7]. Among butchers in the studied abattoirs, the RVF IgG seropositivity rate was $8 \%$. This figure is higher than the overall seroprevalence of $6.0 \%$ among community based general population found in a recent study in the same region [8]. A seroprevalence figure of $7.3 \%$ was found among abattoirs workers in Tanzania in 2004 before 2007 epidemics [9]. A higher rate of $40 \%$ has been documents among abattoir workers in Kenya [7]. Again the higher rate in the Kenyan study could be attributed to cumulative previous exposures to RVF virus. Interestingly, the seropositive abattoir workers were all butchers, among whom the seropositivity rate was $8 \%$. This variability in prevalence may also be explained by mere chance. The seropositive butchers were a Saudi and three Bengalis and were residents of the study region during the outbreak of 20002001. Only the Saudi recalled the fact that he was diagnosed as a case of RVFV infection and most likely the remaining 3 were subclinically infected during the outbreak and none of the rest of the abattoir workers gave a history of any illness during 6 past months. This argument is probably true since the entire sero-negative abattoir workers were appointed after the outbreak of 20002001 and none of them was positive for RVF-specific $\operatorname{IgG}$ or IgM thus ruling out any evidence of previous exposure or recent infection.

While it is difficult to segregate slaughterhouse activities involving exposure to animal tissue, findings during the 1993 outbreak in Egypt demonstrated that those tasks with highest exposure to animal blood, i.e., cutting animals' throats and handling animal parts, were associated with increased risk of infection with RVF virus. This provides further evidence that direct contact with potentially infected animals is a prominent mode of transmission of the virus [10].

The results of the present survey suggest that high-risk, occupationally exposed abattoir workers represent a useful sentinel population for surveillance of RVF, especially in the absence of clinical disease. Abattoir workers in the study regions must adhere to protective measures. 
The present study documented a high prevalence of RVF-specific IgG among those workers compared to the general population. These protective measures should include the wearing of masks, gloves, aprons and other protective barriers. Regular use of soap, water and antiseptics on exposed body parts should be encouraged during their practices. The researchers observed the lack of regular adherence of abattoir workers to these protective measures. More comprehensive training program in the region for abattoir workers is needed. A recent study in Portugal among butchers affirmed education as an important link to the two variables: knowledge and attitudes; customs and environment in abattoirs [11]. The training programs for abattoirs workers in the region should incorporate activities that support skills development relevant to real life situations in which the workers can put information into practice. There is a need to develop training methods that proved to change behavior as well as imparting knowledge.

\section{REFERENCES}

[1] Arishi, H., Ageel, A., Abdu, R.M., et al. (2000) Update: Outbreak of Rift Valley fever-Saudi Arabia, AugustNovember 2000. Morbidity and Mortality Weekly Report, 49, 982-985.

[2] Centers for Disease Control and Prevention (2000) Outbreak of Rift Valley fever-Yemen, August-October 2000. Morbidity and Mortality Weekly Report, 49, 1065-1066.

[3] Madani, T.A., Al-Mazrou, Y.Y., Al-Jeffri, M.H., Mishkhas, A.A., Al-Rabeah, M., Turkistani, A.M., Al-Sayed, M.O., Abodahish, A.A., Khan, A.S., Ksiazek, T.G. and Shobokshi, O. (2003) Rift Valley fever epidemic in Saudi Arabia: Epidemiological, clinical and laboratory characteristics. Clinical Infectious Diseases, 37, 1084-1092. doi:10.1086/378747

[4] Alvarado-Esquivel, C., Liesenfeld, O., Estrada-Martínez, S. and Félix-Huerta, J., (2011) Toxoplasma gondii infection in workers occupationally exposed to raw meat. Occupational Medicine (Lond), 61, 265-269. doi:10.1093/occmed/kqr032

[5] (2006) Health statistics year book. Ministry of Health. Saudi Arabia.

[6] Chamers, P.G. and Swanepoel (1980) Rift Valley fever in abattoir workers. Central African Journal of Medicine, 26, 122-126.

[7] Logan, T.M., Davies, F.G., Linchicum, K.J. and Ksiazek, T.G. (1992) Rift Valley antibody in human sera collected after an outbreak in domestic animals in Kenya. Transactions of the Royal Society of Tropical Medicine and Hygiene, 82, 202-203. doi:10.1016/0035-9203(92)90571-S

[8] Al-Azraqi, T., El Mekki, A.A. and Mahfouz, A. (2012) Rift Valley fever in Southwestern Saudi Arabia: A seroepidemiological study seven years after the outbreak of 2000-2001. Acta Tropica, 123, 111-116. doi:10.1016/j.actatropica.2012.04.007

[9] Swai, E.S. and Schoonman, L. (2009) Prevalence of Rift Valley fever immunoglobulin $\mathrm{G}$ antibody in various occupational groups before the 2007 outbreak in Tanzania. Vector Borne and Zoonotic Diseases, 9, 579-582. doi:10.1089/vbz.2008.0108

[10] Abu, E.R., El-Sharkawy, S., Olson, J., et al. (1996) Prevalence of anti-Rift Valley fever IgM antibodiesin abattoir workers in the Nile delta during the 1993 outbreak in Egypt. Bulletin of the World Health Organization, 76, 155158.

[11] Gomes-Neves, E., Cardoso, C., Araújo, A. and Costa, J. (2011) 2011Meat handlers training in Portugal: A survey on knowledge and practice. Food Control, 22, 501-507. doi:10.1016/i.foodcont.2010.09.036 